Article

\title{
Reactivity of Heteropolymolybdates and Heteropolytungstates in the Cationic Polymerization of Styrene
}

\author{
Ahmed Aouissi *, Zeid Abdullah Al-Othman and Holeil Al-Anezi \\ Chemistry Department, College of Science, King Saud University, Riyadh, Saudi Arabia \\ * Author to whom correspondence should be addressed; E-Mail: aouissed@yahoo.fr.
}

Received: 13 April 2010; in revised form: 28 April 2010 / Accepted: 29 April 2010 /

Published: 5 May 2010

\begin{abstract}
The two heteropolyacids $\mathrm{H}_{3} \mathrm{PW}_{12} \mathrm{O}_{40}$ and $\mathrm{H}_{3} \mathrm{PMo}_{12} \mathrm{O}_{40}$, and their homologous salts $\left(\mathrm{NH}_{4}\right)_{3} \mathrm{PW}_{12} \mathrm{O}_{40}$, and $\left(\mathrm{NH}_{4}\right)_{3} \mathrm{PMo}_{12} \mathrm{O}_{40}$ were prepared and tested in the cationic polymerization of styrene. The results showed that the heteropolytungstates were more reactive than the heteropolymolybdates. It has been found that the yield and the viscosity average molecular weight $\left(\mathrm{M}_{\mathrm{v}}\right)$ of polystyrene are directly proportional to the acidity strength of the heteropolyanions $\left(\mathrm{H}_{3} \mathrm{PW}_{12} \mathrm{O}_{40}>\mathrm{H}_{3} \mathrm{PMo}_{12} \mathrm{O}_{40}>\left(\mathrm{NH}_{4}\right)_{3} \mathrm{PW}_{12} \mathrm{O}_{40}>\right.$ $\left.\left(\mathrm{NH}_{4}\right)_{3} \mathrm{PMo}_{12} \mathrm{O}_{40}\right)$. The highest yield $(68.0 \%)$ and $\mathrm{M}_{\mathrm{v}}(7,930)$ were obtained by using $\mathrm{H}_{3} \mathrm{PW}_{12} \mathrm{O}_{40}$. In addition, $\mathrm{H}_{3} \mathrm{PW}_{12} \mathrm{O}_{40}$ polymerized the styrene under mild conditions and was recyclable, and could behave as a truly heterogeneous catalyst.
\end{abstract}

Keywords: heteropoly compounds; cationic polymerization; polystyrene; solid acid

\section{Introduction}

Modern chemical industry necessitates much more efficient usage of energy and resources, in order to minimize the undesirable environmental impact, competing with the rapidly growing population. In this context solid acid catalysts have attracted much attention in organic synthesis owing to their easy work-up procedures, easy filtration, and minimization of cost and waste generation due to reuse and recycling of these compounds [1]. The advantages of heterogeneous catalysts over homogeneous ones include stability (towards air and moisture), lack of corrosion, ease of handling, recovery and regeneration. Among the heterogeneous catalysts used, numerous works have reported the application of heteropolyanions as new materials in various fields. 
Heteropolyanions are oxoclusters of transition metals such as $\mathrm{W}$ and Mo. They are discrete species, insoluble in non-polar solvents but highly soluble in polar ones without structure change. Due to their unique combination of acid-base and redox properties these kinds of solids have been used successfully as solid catalysts in their acidic or their salt form for acid and redox catalyzed reactions in both homogeneous and heterogeneous media [2-7]. Because of their stronger acidity, they generally exhibit higher catalytic activity than conventional acids, such as sulfuric and nitric acids [8-10]. Recently heteropolyanions had been introduced into the field of polymer science [11-15]. Chen et al. [11] have studied the polymerization of styrene over 12-molybdophosphoric acid. To the best knowledge of the authors, other heteropolyanions with much stronger acidity, namely 12 tungstophosphoric acid were not investigated. Thus, in this paper, the investigation was extended to a series of heteropoly compounds having $\mathrm{W}$ and Mo as added atoms and we have attempted to compare the reactivity between $\mathrm{W}$ and Mo in the cationic polymerization of styrene. It is worth noting that Mo and $\mathrm{W}$ heteropolyoxoanions have attracted much attention in the area of catalytic reactions $[3,12]$.

\section{Results and Discussion}

\subsection{Catalyst characterization}

\subsubsection{Infrared spectra}

The spectra of the catalysts used are shown in Figure 1. The IR spectra have been assigned according to [16,17]. The main characteristic features of the Keggin structure are observed at $1,080-1,060 \mathrm{~cm}^{-1}\left(v_{\mathrm{as}} \mathrm{P}-\mathrm{O}_{\mathrm{a}}\right)$, at $990-960 \mathrm{~cm}^{-1}\left(v_{\mathrm{as}} \mathrm{M}-\mathrm{O}_{\mathrm{d}}\right)$, at $900-870 \mathrm{~cm}^{-1}\left(v_{\mathrm{a}} \mathrm{M}-\mathrm{O}_{\mathrm{d}}-\mathrm{M}\right)$, and at $810-760 \mathrm{~cm}^{-1}\left(v_{\mathrm{as}} \mathrm{M}-\mathrm{O}_{\mathrm{c}}-\mathrm{M}\right)$, respectively $(\mathrm{M}=\mathrm{W}$ or $\mathrm{Mo})$.

Figure 1. IR spectra of: a) $\mathrm{H}_{3} \mathrm{PW}_{12} \mathrm{O}_{40} ;$ b) $\mathrm{H}_{3} \mathrm{PMo}_{12} \mathrm{O}_{40}$; c) $\left(\mathrm{NH}_{4}\right)_{3} \mathrm{PW}_{12} \mathrm{O}_{40}$;
$\left(\mathrm{NH}_{4}\right)_{3} \mathrm{PMo}_{12} \mathrm{O}_{40}$. $\left(\mathrm{NH}_{4}\right)_{3} \mathrm{PMO}_{12} \mathrm{O}_{40}$

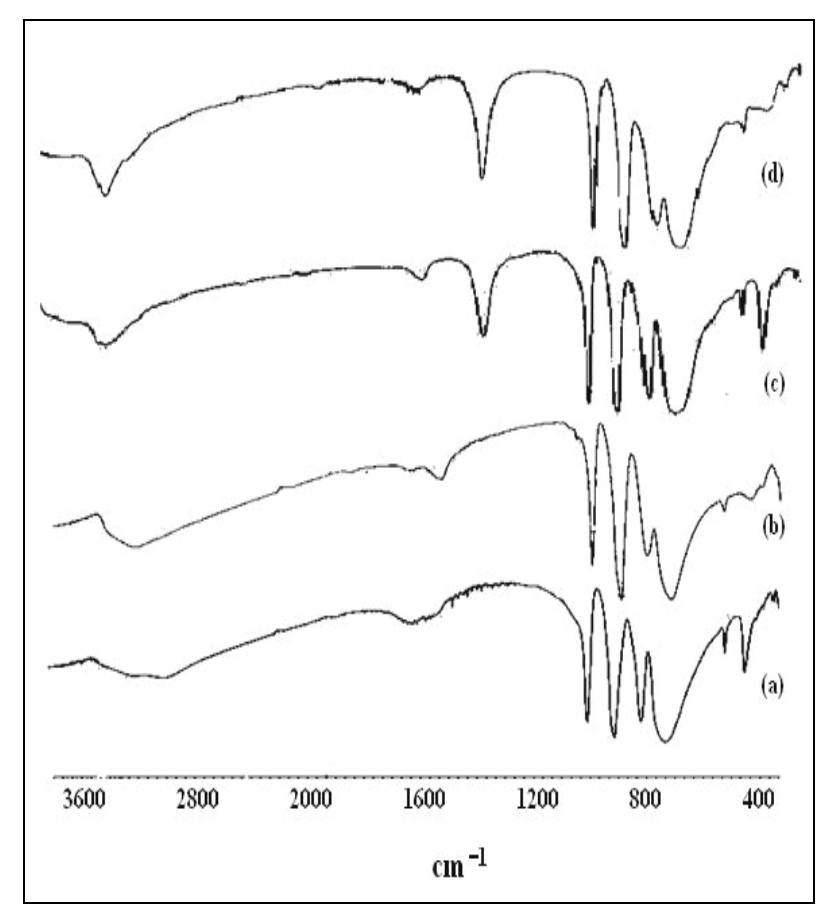


Besides the above characteristic frequencies of the heteropolyanions, in spectra c) and d) there is a broad band at $3,212 \mathrm{~cm}^{-1}$, and a sharp band at $1,414 \mathrm{~cm}^{-1}$, which are characteristic absorptions of the $\mathrm{NH}_{4}{ }^{+}$group, which indicates the formation of the ammonium salts $\left(\mathrm{NH}_{4}\right)_{3} \mathrm{PW}_{12} \mathrm{O}_{40}$ and $\left.\mathrm{NH}_{4}\right)_{3} \mathrm{PMo}_{12} \mathrm{O}_{40}[16]$.

\subsubsection{Characterization of the polymer product}

The results showed that these four solid acid catalysts induced the polymerization of styrene, as evidenced by ${ }^{13} \mathrm{C}-\mathrm{NMR}$ (Figure 2).

Figure 2. $100 \mathrm{MHz}{ }^{13} \mathrm{C}-\mathrm{NMR}$ spectrum in $\mathrm{CDCl}_{3}$ of polystyrene obtained with $\mathrm{H}_{3} \mathrm{PW}_{12} \mathrm{O}_{40}$ catalyst.

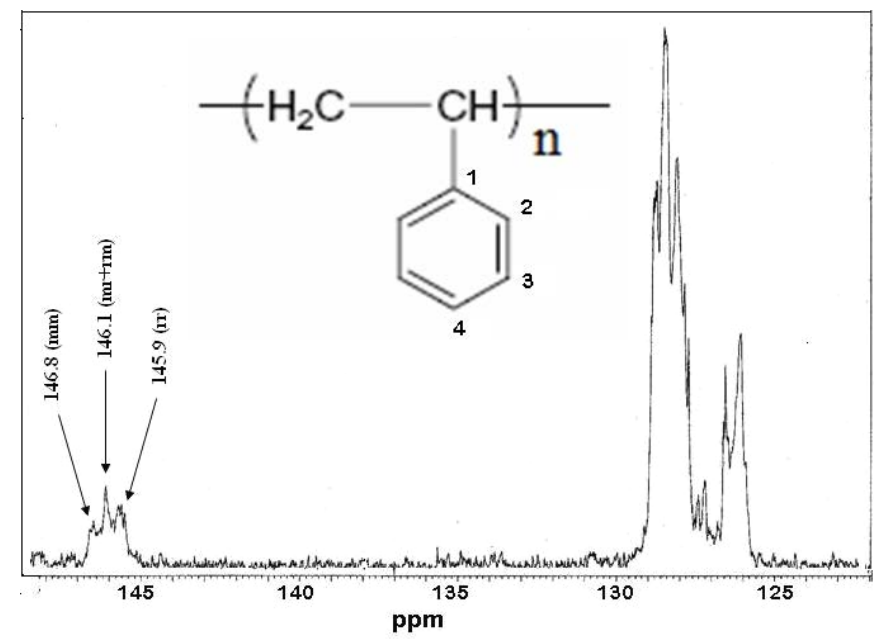

The analysis of the ${ }^{13} \mathrm{C}-\mathrm{NMR}$ spectra showed the signals of aliphatic carbon atoms at 40.4 and $43.8 \mathrm{ppm}$ and signals corresponding to the meta, ortho and para carbon atoms of the aromatic ring in the region between 125.5 and $128.0 \mathrm{ppm}$. The aromatic $\mathrm{C}_{1}$-carbons gave three signals at $145.3,145.7$ and $146.1 \mathrm{ppm}$ attributed to the $(\mathrm{rr}),(\mathrm{mr}+\mathrm{rm})$ and $(\mathrm{mm})$ diads, respectively, according to [18]. It was found that this kind of catalyst essentially gave a mixture of diads $(\mathrm{mr}+\mathrm{rm})(65-70 \%), \mathrm{rr}(20-25 \%)$ and a small quantity of diad $\mathrm{mm}(10-15 \%)$.

Figure 3. The DSC thermograms of polystyrene material obtained at $20{ }^{\circ} \mathrm{C} / \mathrm{min}$ heating and cooling rate.

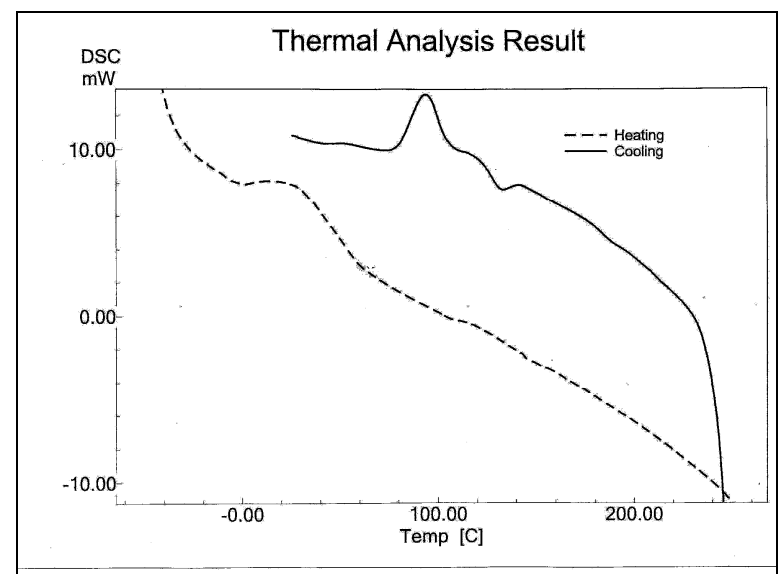


Differential scanning calorimetry studies characterized further these polystyrene materials. Figure 3 shows a glass transition temperature $\left(\mathrm{T}_{\mathrm{g}}\right)$, melting temperature $\left(\mathrm{T}_{\mathrm{m}}\right)$ and crystallization temperature $\left(\mathrm{T}_{\mathrm{c}}\right)$ at $58.2^{\circ} \mathrm{C}, 149.9^{\circ} \mathrm{C}$, and $94.5^{\circ} \mathrm{C}$ respectively.

\subsection{Catalyst reactivity}

\subsubsection{Effect of the styrene/DCM ratio}

Since the bulk polymerization of styrene was rapidly stopped and the magnetic bar could not stir, we decided to perform the polymerization reactions in a solvent. The styrene polymerization reactions were thus carried out in dichloromethane (DCM) in the presence of $\mathrm{H}_{3} \mathrm{PW}_{12} \mathrm{O}_{40}$ as catalyst in order to examine the effect of the solvent ratio on the catalytic properties of the catalyst and therefore select the suitable St/solvent ratio. The polymerization reactions were catalyzed by $10 \mathrm{mg}$ and $25 \mathrm{mg}$ of $\mathrm{H}_{3} \mathrm{PW}_{12} \mathrm{O}_{40}$. The results are shown in Figure 4. It can be seen from this figure that for both catalyst amounts, the best yield was obtained for the volume ratio $\mathrm{St} / \mathrm{DCM}=0.4$.

Figure 4. Effect of St/DCM volume ratio on styrene polymerization using $\mathrm{H}_{3} \mathrm{PW}_{12} \mathrm{O}_{40}$ catalyst. Reaction conditions : $\mathrm{T}=25^{\circ} \mathrm{C}$; catalyst amount $10 \mathrm{mg}$ and $25 \mathrm{mg}$; reaction time $160 \mathrm{~min}$.

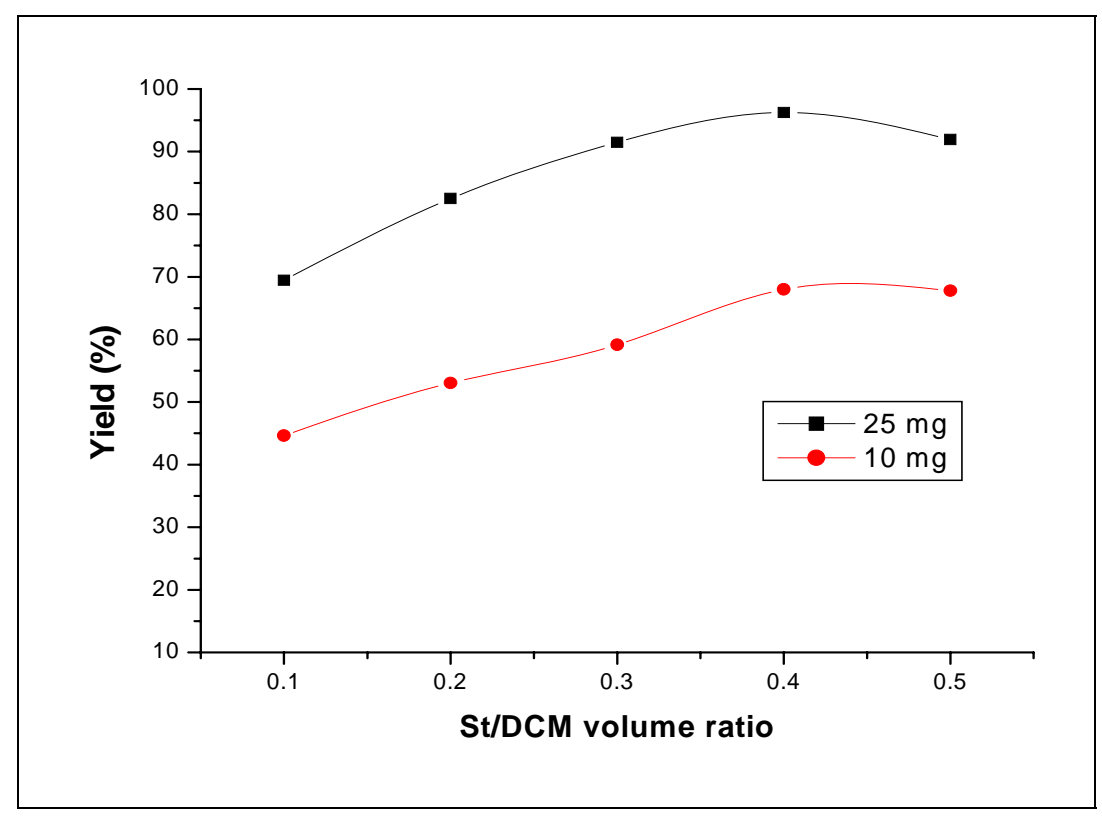

\subsubsection{Reactivity of $\mathrm{W}$ and Mo in the heteropolyacids}

Figure 5 shows the effect of the reaction time on the yields. It can be seen from the figure that the yields increased linearly for both heteropolyacids. During all the time of the polymerization, the yield of the 12-tungstophosphoric acid reaction remained higher than that obtained with 12-molybdophosphoric acid. The yields obtained at $5 \mathrm{~h}$ of reaction time with $\mathrm{H}_{3} \mathrm{PW}_{12} \mathrm{O}_{40}$ and $\mathrm{H}_{3} \mathrm{PMo}_{12} \mathrm{O}_{40}$ are $68.0 \%$ and $45.0 \%$ respectively. The average molecular weights obtained also at this reaction time are 9,250 and 5,560, respectively. As $\mathrm{H}_{3} \mathrm{PW}_{12} \mathrm{O}_{40}$ has stronger acidity than that $\mathrm{H}_{3} \mathrm{PMo}_{12} \mathrm{O}_{40}$, these results suggest that strength acidity of the catalyst play an important role for the formation and the physical properties of polystyrene $\left(\mathrm{H}_{3} \mathrm{PW}_{12} \mathrm{O}_{40}>\mathrm{H}_{3} \mathrm{PMo}_{12} \mathrm{O}_{40}\right.$ [7]). Figure 6 shows the yield of 
polystyrene obtained for various amounts for both catalysts, $\mathrm{H}_{3} \mathrm{PW}_{12} \mathrm{O}_{40}$ and $\mathrm{H}_{3} \mathrm{PMo}_{12} \mathrm{O}_{40}$. It can be seen from this figure that both catalysts have remarkably the same tendency; however, the 12-tungstophosphoric acid (W as added atom) gives a higher yield than that of 12-molybdophosphoric acid (Mo as added atoms). For low catalyst amounts, one can see that the gap in the yield values between the two catalysts is high, whereas for higher amounts, the gap decreased.

Figure 5. Effect of the reaction time on the styrene polymerization (in dichloromethane) over $\mathrm{H}_{3} \mathrm{PW}_{12} \mathrm{O}_{40}$ and $\mathrm{H}_{3} \mathrm{PMo}_{12} \mathrm{O}_{40}$ catalysts. Polymerization was carried out at $25{ }^{\circ} \mathrm{C}$ using $10 \mathrm{mg}$ of catalyst.

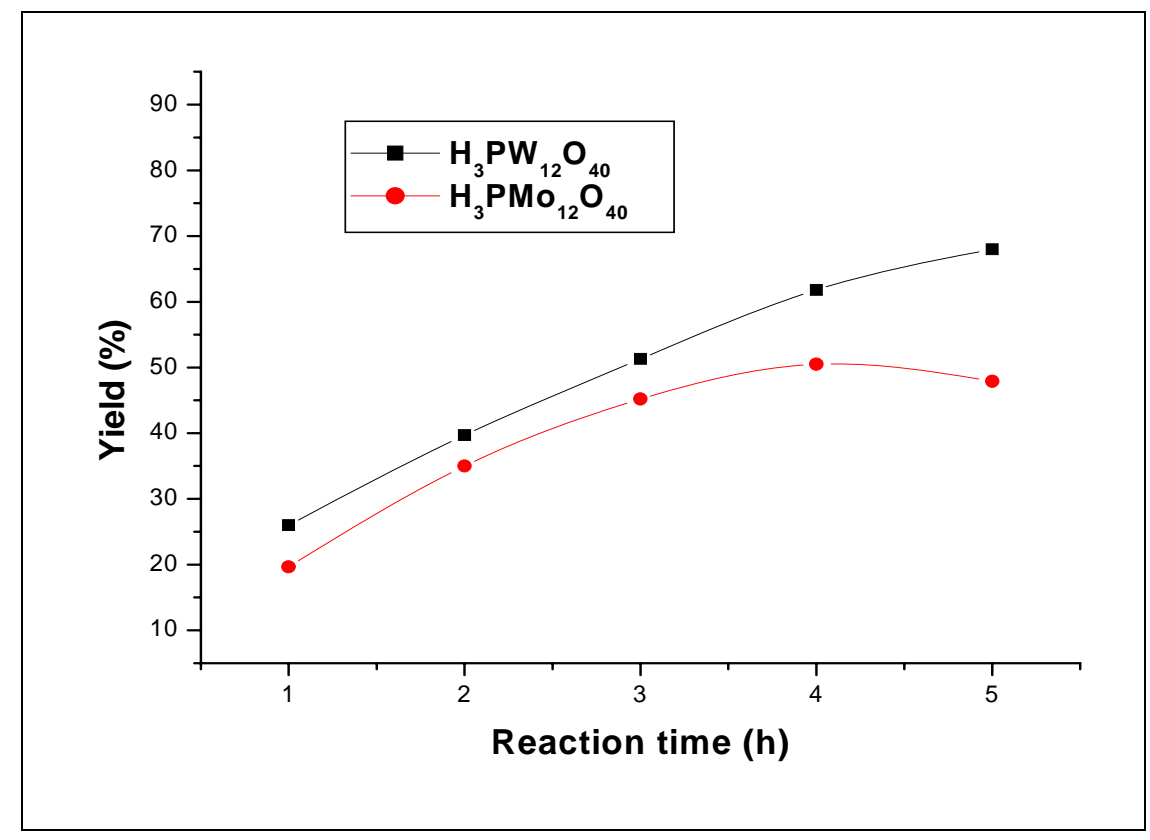

Figure 6. Effect of the amount of catalyst on styrene polymerization (in dichloromethane) using $\mathrm{H}_{3} \mathrm{PW}_{12} \mathrm{O}_{40}$ and $\mathrm{H}_{3} \mathrm{PMo}_{12} \mathrm{O}_{40}$ catalysts. Polymerization was carried out at $25{ }^{\circ} \mathrm{C}$ during $5 \mathrm{~h}$.

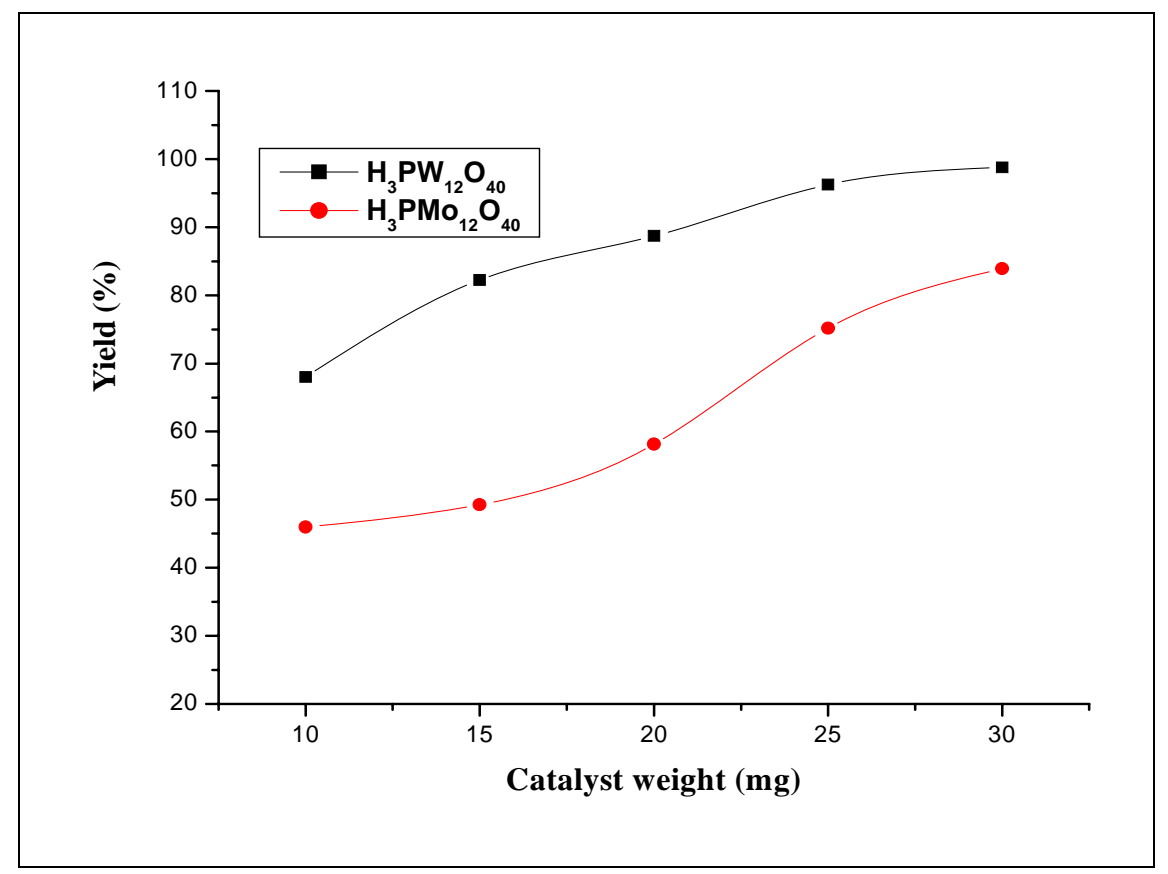




\subsubsection{Reactivity of $\mathrm{W}$ and $\mathrm{Mo}$ in ammonium salts}

The effect of the reaction time on the polymerization was shown in Figure 7. When the protons of the heteropolyacids where replaced by ammonium cations $\left(\mathrm{NH}_{4}{ }^{+}\right)$, the obtained ammonium salts showed a dramatic decrease in the polymerization rate. In fact, no measurable yields were observed before $2 \mathrm{~h}$ of reaction time for both solids. Thus to obtain significant conversions, we carried out the polymerization for $12 \mathrm{~h}$. Like their homologous heteropolyacids, the results showed that when the W atoms were replaced by their homologous Mo atoms, a decrease of the polymerization rate was observed.

Figure 7. Effect of the reaction time on the styrene polymerization (in dichloromethane) using $\left(\mathrm{NH}_{4}\right)_{3} \mathrm{PW}_{12} \mathrm{O}_{40}$ and $\left(\mathrm{NH}_{4}\right)_{3} \mathrm{PMo}_{12} \mathrm{O}_{40}$ catalysts. Polymerization was carried out at $25^{\circ} \mathrm{C}$ using $10 \mathrm{mg}$ of catalyst.

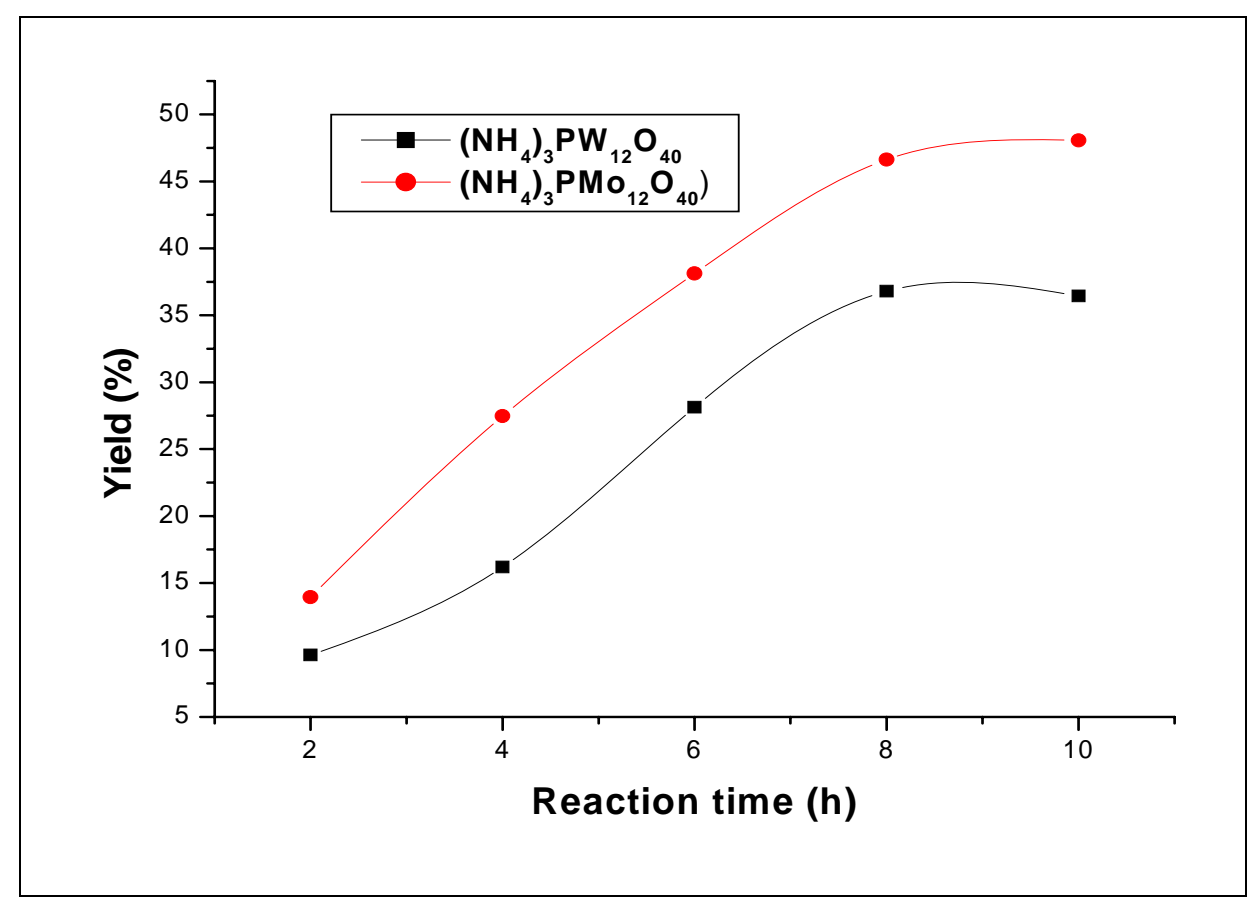

The yields obtained at $12 \mathrm{~h}$ of reaction time with $\left(\mathrm{NH}_{4}\right)_{3} \mathrm{PW}_{12} \mathrm{O}_{40}$ and $\left(\mathrm{NH}_{4}\right)_{3} \mathrm{PMo}_{12} \mathrm{O}_{40}$ are $48.1 \%$ and $36.8 \%$, respectively. The average molecular weights obtained at this reaction time are 5,657 and 4,095 , respectively. As the acidity of $\mathrm{H}_{3} \mathrm{PW}_{12} \mathrm{O}_{40}$ is stronger than that of $\mathrm{H}_{3} \mathrm{PMo}_{12} \mathrm{O}_{40}$, these results suggest that strength acidity of the catalyst play an important role for the formation and the physical properties of polystyrene. The effect of the catalyst amount on the polymerization was depicted in Figure 8. The results show that for both catalysts the yields have remarkably the same tendency; however, the ammonium salt containing the $\mathrm{W}$ atoms presents a slight higher conversion than that containing the Mo ones.

If we take into account the yields obtained for 5 hours of polymerization with this series of catalysts; $\mathrm{H}_{3} \mathrm{PW}_{12} \mathrm{O}_{40}(68.0 \%), \mathrm{H}_{3} \mathrm{PMo}_{12} \mathrm{O}_{40}(45.0 \%),\left(\mathrm{NH}_{4}\right)_{3} \mathrm{PW}_{12} \mathrm{O}_{40}(33.1 \%)$, and $\left(\mathrm{NH}_{4}\right)_{3} \mathrm{PMo}_{12} \mathrm{O}_{40}$ $(22.6 \%)$ we can see that the reactivity is directly proportional to the acidity strength of the heteropolyanions $\left(\mathrm{H}_{3} \mathrm{PW}_{12} \mathrm{O}_{40}>\mathrm{H}_{3} \mathrm{PMo}_{12} \mathrm{O}_{40}>\left(\mathrm{NH}_{4}\right)_{3} \mathrm{PW}_{12} \mathrm{O}_{40}>\left(\mathrm{NH}_{4}\right)_{3} \mathrm{PMo}_{12} \mathrm{O}_{40}\right.$ [7]). Thus, this result indicates that strong Brønsted acidity is suitable for the cationic polymerization of styrene. 
Figure 8. Effect of the amount of catalyst on styrene polymerization (in dichloromethane) using $\left(\mathrm{NH}_{4}\right)_{3} \mathrm{PW}_{12} \mathrm{O}_{40}$ and $\left(\mathrm{NH}_{4}\right)_{3} \mathrm{PMo}_{12} \mathrm{O}_{40}$ catalysts. Polymerization was carried out at $25^{\circ} \mathrm{C}$ during $12 \mathrm{~h}$.

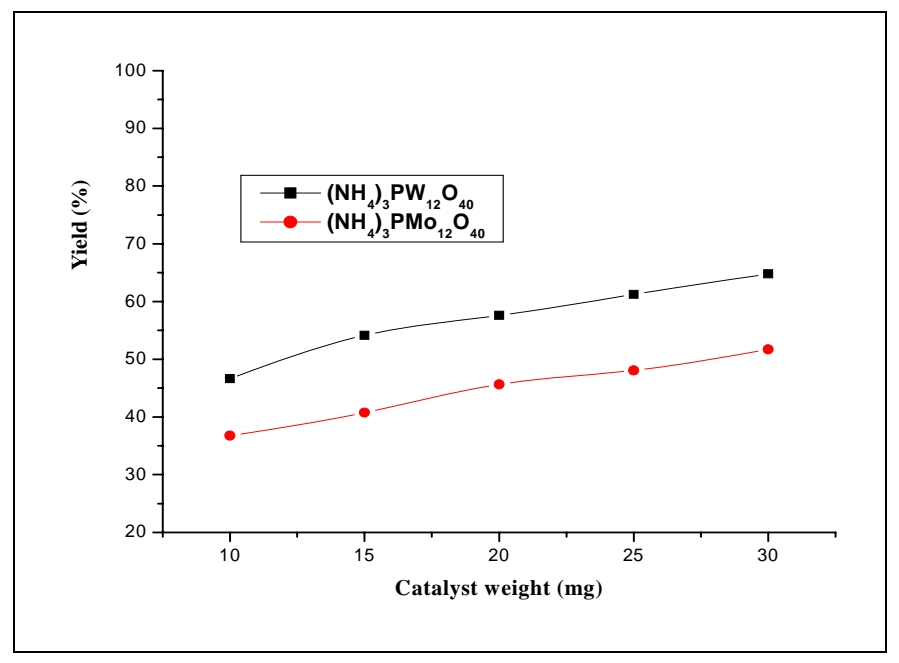

\subsubsection{Effect of reaction temperature}

The effect of the polymerization temperature on the conversion was examined by keeping the composition of the $\mathrm{St} / \mathrm{DCM}=0.4$. The results are shown in Figure 9. It can see from this figure that the rate of polymerization increases with the increase in temperature. The yield increases rapidly from $67.8 \%$ to $95.3 \%$ when the temperature increases from $25{ }^{\circ} \mathrm{C}$ to $50{ }^{\circ} \mathrm{C}$. Then after, it remains stable at about $95.8 \%$ when the temperature increases from 50 to $60^{\circ} \mathrm{C}$.

Figure 9. Influence of the reaction temperature on the polymerization of styrene. Polymerization was carried out in dichloromethane $(\mathrm{St} / \mathrm{DCM}$ (volume ratio) $=0.4$.) using $0.025 \mathrm{~g}$ of $\mathrm{H}_{3} \mathrm{PW}_{12} \mathrm{O}_{40}$ catalyst.

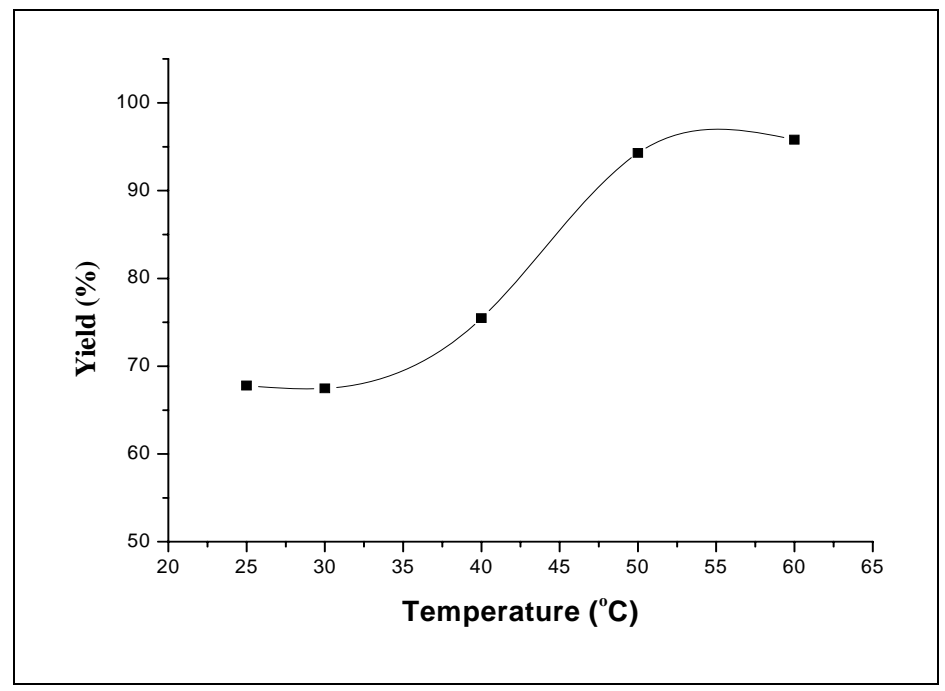

\subsubsection{Catalyst recycling}

Much effort has been devoted not only to the development of superior catalysts but also to finding ways to enable their repeated use. In order to investigate this possibility for $\mathrm{H}_{3} \mathrm{PW}_{12} \mathrm{O}_{40}$, this latter was 
separated from the reaction mixture by filtration after the reaction, regenerated by washing with cyclohexane for five times, dried at 150 over night, and used again in a fresh reaction. The IR spectra of the fresh and recycled catalyst are shown in Figure 10. It can be seen from the figure that the Keggin structure of the catalyst did not change. The regenerated catalyst was used for the recycling study under the same reaction conditions. When the reaction was carried out at $60{ }^{\circ} \mathrm{C}$ by the fresh and the used catalyst, the yield obtained is $95.8 \%$ and $72.1 \%$, respectively. This result confirms the recyclable applicability of $\mathrm{H}_{3} \mathrm{PW}_{12} \mathrm{O}_{40}$ for the polymerization of styrene.

Figure 10. FTIR spectra of fresh and used $\mathrm{H}_{3} \mathrm{PW}_{12} \mathrm{O}_{40}$ catalysts.

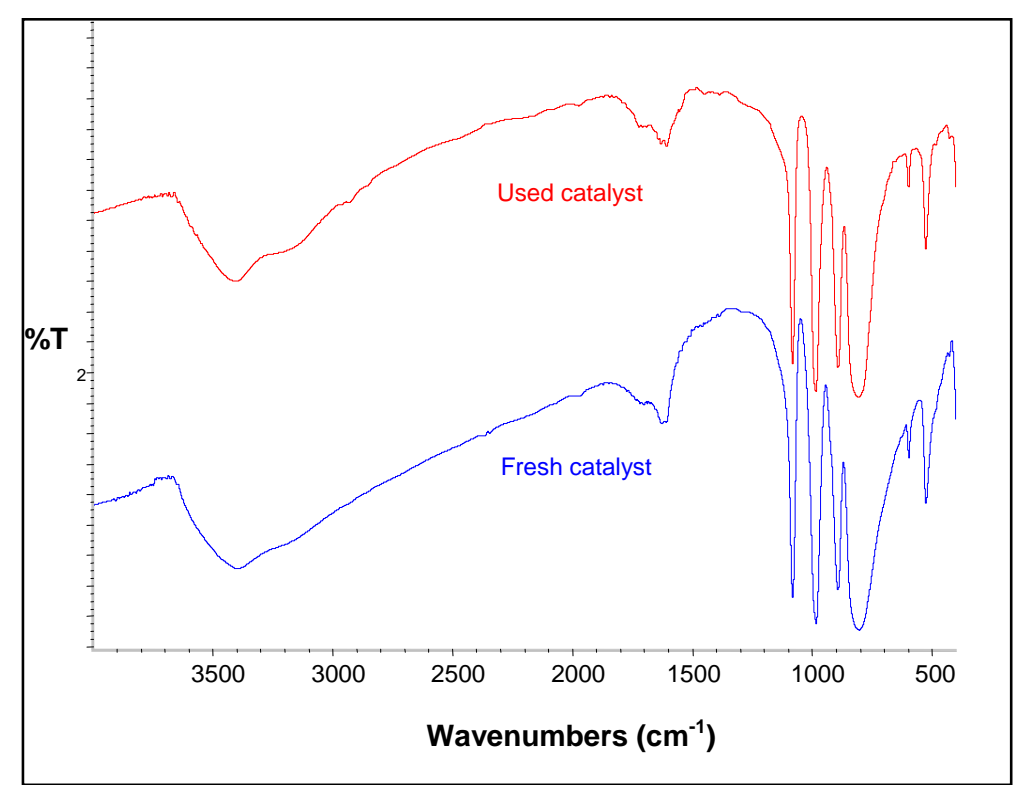

\section{Experimental}

\subsection{Preparation of the catalysts}

$\mathrm{H}_{3} \mathrm{PW}_{12} \mathrm{O}_{40} \cdot 13 \mathrm{H}_{2} \mathrm{O}$ and $\mathrm{H}_{3} \mathrm{PMo}_{12} \mathrm{O}_{40} \cdot 13 \mathrm{H}_{2} \mathrm{O}$ (abbreviated $\mathrm{H}_{3} \mathrm{PW}_{12} \mathrm{O}_{40}$ and $\mathrm{H}_{3} \mathrm{PMo}_{12} \mathrm{O}_{40}$ ) were prepared in a classical way as described in the literature [16]. $\left(\mathrm{NH}_{4}\right)_{3} \mathrm{PW}_{12} \mathrm{O}_{40} \cdot 4 \mathrm{H}_{2} \mathrm{O}$ and $\left(\mathrm{NH}_{4}\right)_{3} \mathrm{PMo}_{12} \mathrm{O}_{40} \cdot 4 \mathrm{H}_{2} \mathrm{O}$ (abbreviated $\left(\mathrm{NH}_{4}\right)_{3} \mathrm{PW}_{12} \mathrm{O}_{40}$ and $\left(\mathrm{NH}_{4}\right)_{3} \mathrm{PMo}_{12} \mathrm{O}_{40}$ ) were prepared from their homologous acids using the following procedure: the compound is precipitated by adding slowly the stoichiometric required amount of ammonium carbonate $\left(\mathrm{NH}_{4}\right)_{2} \mathrm{CO}_{3}$ to an aqueous solution of $\mathrm{H}_{3} \mathrm{PM}_{12} \mathrm{O}_{40}(\mathrm{M}=\mathrm{W}$; Mo). The insoluble ammonium salt is immediately precipitated. Then after the salt was filtrered off, washed with water and dried overnight at $120^{\circ} \mathrm{C}$.

\subsection{Procedure of polymerization}

The bulk polymerizations of styrene were carried out in a stirred flask at $25^{\circ} \mathrm{C}$ for a definite time. Typically, a fixed amount of catalyst was added to $10 \mathrm{~mL}$ of styrene and $4 \mathrm{~mL}$ of dichloromethane under stirring. The polymerization was quenched by the addition of saturated $\mathrm{NaOH}$ aqueous solution. The resulting precipitated polymer was filtrated off, then dissolved in butanone to removing the catalyst, which is insoluble in butanone. The recovered polymer was precipitated into aqueous ethanol 
solution, filtrated off, dried at $40-50^{\circ} \mathrm{C}$ under vacuum, and weighed. Then, the polymer was purified by dissolving it in chloroform and precipitation into ethanol for characterization.

Catalysts and polymers characterization

The Keggin structure of the prepared heteropolyanions was checked by infrared (IR) spectroscopy. IR spectra were recorded with a GENESIS II- FTIR (4000-400 $\left.\mathrm{cm}^{-1}\right)$ infrared spectrometer as $\mathrm{KBr}$ pellets. ${ }^{13} \mathrm{C}-\mathrm{NMR}$ spectra were recorded on a Jeol ECLIPSE $400 \mathrm{MHz}$ spectrophotometer using tetramethylsilane (TMS) as external reference. The chemical shifts are given in ppm. The glass transition temperature of the pure components was measured with a DSC (Setaram Labsys DSC 16), previously calibrated with indium, at $20^{\circ} \mathrm{C} / \mathrm{min}$ rate. The samples of $10-15 \mathrm{mg}$ were preheated to $200{ }^{\circ} \mathrm{C}$ under nitrogen atmosphere and kept at that temperature for $10 \mathrm{~min}$ to ensure total elimination of solvent. The data were collected from the second and third scan. No degradation phenomenon of PS was observed in all thermograms. The glass transition temperature was taken as the midpoint in the heat capacity. Molecular weights were determined by measurement of viscosity. Inherent viscosity of poly(styrene) obtained were measured in toluene solution at $25{ }^{\circ} \mathrm{C}$ by using an Ubbelohde type viscometer. The viscosity average molecular weight $\left(\mathrm{M}_{\mathrm{v}}\right)$ was calculated by the following equation: $[\eta]=9.77 \times 10^{-3} \cdot \mathrm{M}_{\mathrm{v}}^{0.73}[19]$.

\section{Conclusions}

The polymerization of styrene in dichloremethane was performed using $\mathrm{H}_{3} \mathrm{PW}_{12} \mathrm{O}_{40}, \mathrm{H}_{3} \mathrm{PMo}_{12} \mathrm{O}_{40}$, $\left(\mathrm{NH}_{4}\right)_{3} \mathrm{PMo}_{12} \mathrm{O}_{40}$, and $\left(\mathrm{NH}_{4}\right)_{3} \mathrm{PMo}_{12} \mathrm{O}_{40}$ as catalysts. It has been found that the catalysts containing $\mathrm{W}$ were more reactive than those containing Mo. $\mathrm{H}_{3} \mathrm{PW}_{12} \mathrm{O}_{40}$ was the most effective catalyst in terms of yield and $\mathrm{M}_{\mathrm{v}}$ due to its stronger Brønsted acidity. The use of $\mathrm{H}_{3} \mathrm{PW}_{12} \mathrm{O}_{40}$ as a heterogeneous solid acid catalyst, instead of the usual soluble inorganic acids, is a contribution to a reduction of waste. In fact, this latter can polymerize styrene under mild conditions and a simple filtration is sufficient to recover the catalyst which can be reused.

\section{References}

1. Alizadeh, M.H.; Razavi, H.; Bamoharram, F.F.; Daneshvar, K. The oxidative cleavage of carbontin bond catalyzed by heteropolyacids of molybdenum. J. Mol. Catal. A: Chem. 2003, 206, 89-93.

2. Hill, C.L.; Posser-McCarthy, C.M. Homogeneous catalysis by transition-metal oxygen anion clusters. Coord. Chem. Rev. 1995, 143, 407-455.

3. Mizuno, N.; Misono, M. Heterogeneous Catalysis. Chem. Rev. 1998, 98, 199-218.

4. Okuhara, T.; Mizuno, N.; Misono, M. Catalytic Chemistry of Heteropoly Compounds. Adv. Catal. M. 1996, 41, 113-252.

5. Corma, A. Inorganic Solid Acids and Their Use in Acid-Catalyzed Hydrocarbon Reactions. Chem. Rev. 1995, 95, 559-614.

6. Kozhevnikov, I.V. Heteropoly Acids and Related Compounds as Catalysts for Fine Chemical Synthesis. Catal. Rev. -Sci. Eng. 1995, 37, 311-352. 
7. Kozhevnikov I.V. Catalysis by Heteropoly Acids and Multicomponent Polyoxometalates in Liquid-Phase Reactions. Chem. Rev. 1998, 98, 171-198.

8. Misono M. Unique acid catalysis of heteropoly compounds (heteropolyoxometalates) in the solid state. Chem. Commun. 2001, 13, 1141-1152.

9. Heravi, M.M.; Sadjadi, S. Recent Developments in Use of Heteropolyacids, Their Salts and Polyoxometalates in Organic Synthesis. J. Iran. Chem. Soc. 2009, 6, 1-54.

10. Moffat, J.B. Catalysis by solid state oxometalates. Chem. Eng. Commun. 1989, 83, 9-29.

11. Chen, D.; Xue, Z.; Su, Z. Dual role study of 12-molybdophosphoric acid on styrene polymerization. J. Mol. Catal. A: Chem. 2004, 208, 91-95

12. Mizuno, N.; Misono, M. Heteropolyanions in catalysis. J. Mol. Catal. 1994, 86, 319-342.

13. Aouissi, A.; Al-Deyab S.S.; Al-Shehri, H. Cationic Ring-Opening Polymerization of Tetrahydrofuran with Keggin-type heteropoly compounds as Solid acid catalysts. Chin. J. Polym. Sci. 2010, 28, 305-310.

14. Misono, M. Heterogeneous catalysis by heteropoly compounds of molybdenum and tungsten. Catal. Rev. Sci. Eng. 1987, 29, 269-321.

15. Misono, M.; Mizuno, N.; Katamura, K.; Kasai, A.; Konishi, Y.; Sakata, K.; Okuhara, T.; Yoneda, Y. Catalysis by Heteropoly Compounds. III. The Structure and Properties of 2-Heteropolyacids of Molybdenum and Tungsten $\left(\mathrm{H}_{3} \mathrm{PMo}_{12-x} \mathrm{~W}_{x} \mathrm{O}_{40}\right)$ and Their Salts Pertinent to Heterogeneous Catalysis. Bull. Chem. Soc. Jpn. 1982, 55, 400-406.

16. Rocchiccioli-Deltcheff, C.; Fournier, M.; Franck, R.; Thouvenot, R. Vibrational investigations of polyoxometalates. Evidence for anion-anion interactions in molybdenum (VI) and tungsten (VI) compounds related to the Keggin structure. Inorg. Chem. 1983, 22, 207-216.

17. Rocchiccioli-Deltcheff, C.; Fournier, M. Catalysis by Polyoxometalates. Part 3,--Influence of vanadium (V) on the thermal Stability of 12-Metallophosphoric Acids from In Situ Infrared studies. J. Chem. Soc. Faraday Trans. 1991, 87, 3913-3920.

18. Pham, Q.-T.; Petiaud, R. Spectres RMN des Polymeres 1H-13C. SCM: Paris, France, 1980; Volume 1.

19. Wagner, H.L. The Mark--Houwink--Sakurada Equation for the Viscosity of Atactic Polystyrene. J. Phys. Chem. Ref. Data 1985, 4, 1101-1106.

Sample Availability: Samples of the compounds are available from the authors.

(C) 2010 by the authors; licensee MDPI, Basel, Switzerland. This article is an open-access article distributed under the terms and conditions of the Creative Commons Attribution license (http://creativecommons.org/licenses/by/3.0/). 